The Quarterly Journal of Austrian Economics

Volume 23 | NO. 2 | 131-151 | SUMMER 2020 WWW.QJAE.ORG

\title{
Corporate Risk Evaluation in the Context of Austrian Business CyCle Theory
}

JOANNA KRUK*

JeL Classification: B53, E22, E40, E52, G31, G32

Aвstract: This paper expands Fuller's (2013) analysis of the net present value and interest rate changes in the context of the Austrian Business Cycle Theory. During the boom phase of the business cycle, the economy shifts to a more risky position as the result of entrepreneurs' profit targeting. To quantify this risk the duration, defined as the number of periods that elapse before the average present value dollar is received from a stream of cash flows, can be used. The new risk-adjusted net present value is created after applying the duration to capital asset pricing model determining the discount rate that should be used to calculate the present value of the project.

\section{INTRODUCTION}

$\mathrm{T}$ he Austrian business cycle theory (ABCT) gained the interest and endorsement of non-Austrians as a valid theory shortly after the outbreak of the $2007 / 08$ crisis. Then, major focus was placed on macrolevel aggregates such as the volume of loans, the threat of large scale bankruptcy or the supply of money. Little attention was paid to the analysis of corporate finance and the causes of

* Joanna Kruk (jkruk67@gmail.com) is a recent graduate of the Cracow University of Economics and Jagiellonian University. 
companies' erroneous decisions about initiating and carrying out unprofitable undertakings. One direct cause of the collapse was identified as cheap credit, which engenders a reallocation of resources between stages of production. That is inconsistent with the intertemporal preferences of consumers. In particular, lowering the interest rate below its natural level causes production to become more future-oriented. Artificially low interest rates are not only the cause of incurring new debts by companies, but are also the reason why less efficient companies enter the market. Due to the poor quality of their projects, these less efficient companies are more likely to mobilize necessary funds if funds are less limited, which is the result of expansionary monetary policy. Correspondingly, there are numerous entrepreneurs that will receive investment funds only when credit is "easy." (Engelhardt, 2013) Moreover, erroneous decisions to engage more resources to projects which cannot be successfully completed are implemented, making the situation worse than it otherwise would be.

The aim of this paper is to analyze corporate finance from an ABCT perspective with a focus on the excessive risk-taking by companies. While the main literature about the business cycle focuses on the effects of certain policies on the aggregate and general shift of the economy to more risky positions, the motivation of financial decisions on a micro-level can shed new light on the foundations of the emergence of the business cycle. The vast difference between the profitability of an investment project relative to the interest rate change was previously discussed by Fuller (2013) using the net present value and the marginal efficiency of capital to show how interest rates affect the intertemporal allocation of capital and shift the resources to more roundabout projects. Enriching the analysis in risk assessment could lead to a further conclusion regarding the subject. One of the frequently used risk measures is duration, used in capital budgeting and precisely described by Blocher and Clyde (1979) and Johnson (2005).

In this paper, we plan to analyze previous work on the cycle effects on the microenvironment from the Austrian perspective, along with financial literature research on risk assessment, in order to try to capture the impact of interest rates changes based on financial decisions of firms with on numeric examples. 


\section{THE CORPORATE APPROACH TO THE AUSTRIAN BUSINESS CYCLE THEORY}

The Austrian business cycle theory was developed in the first half of the $20^{\text {th }}$ century, mostly by Ludwig von Mises and Friedrich von Hayek. The main focus of the theory was placed on the intertemporal coordination and allocation of resources. In the market economy, the role of price signals was emphasized, as it is the major indicator of entrepreneurs' success in fulfilling their clients' demands. Special attention was paid to interest rates since the core of the ABCT is how artificially low-interest rates, which are falling below their natural level, influence the economic activity of agents.

As formulated by Rothbard (1978), the unhampered market interest rate is determined only by the "time-preferences" of the agents. People choose money right now over a promise made in the present to receive the same amount of money in the future, which means that their time preference is positive. Time preference also indicates the distribution of people's income between savings and consumption. When the interest rate falls as the result of government intervention, rather than as a change in people's preferences, an artificial boom starts. Agents are deceived into thinking that there is a greater amount of savings available for their investment projects, so they begin to engage more capital, particularly in lengthy and time-consuming undertakings, which previously were unprofitable due to the higher cost of financing them.

The main focus of Austrian economists is placed on emphasizing the disruption of intertemporal resources allocated between stages of production, resulting in malinvestments. At the later stage, these projects turn out to be impossible to complete since there are not enough resources to finish all undertakings initiated during the boom episode. This argument was originally formulated by Ludwig von Mises: "Projects which would not have been thought profitable if the rate of interest had not been influenced by the manipulations of the banks, and which, therefore, would not have been undertaken, are nevertheless found profitable and can be initiated." (Mises 1912, 26)

In the microscale during the expansionary phase of the business cycle, firms will prefer to expand production. Since the interest rate is regarded not only as a cost factor but also as a factor of capitalization, decreasing the interest rate creates an incentive for 
investments in fixed capital by way of capitalization of future yields (Machlup 1935). This is the effect of the increased present value of future return, which is capitalized at the new, lowest interest rate. This reasoning applies to both lowering interest rates directly by the central bank and to credit expansion. In the second scenario, the newly available funds push down the interest rate and create the impression that there are more resources available for investment in lengthy projects. At the same time, the decreased interest rate is the reason people are less willing to keep their income as savings, thus the further discrepancy between real and natural interest rate is created (Engelhardt 2012).

The main reason for keeping interest rates low is to boost the economic activity of agents. As a direct consequence, on a corporate finance level, it causes an increase in debt to capital ratio but also has an effect on capital budgeting decisions as described by Cwik (2008). Firms tend to not only increase the volume on investments but also replace investment in working capital with investment in fixed capital, widening the distance between real-time preference and the one imposed by the nominal interest rates. After the boom ends, these projects are abandoned as they are no longer able to generate positive cash flows. Some of the fixed capital used in undertaking can be moved to other projects, which was described by Wood (1984) as the illusion of depression: when companies decide to quit unprofitable undertakings, thus causing a decline in economic activity, but releasing the necessary resources for more effective projects. The resources which cannot be engaged in another project due to their specifics are considered sunk costs. ${ }^{1}$

\section{INFLUENCE OF INTEREST RATE CHANGES ON THE NPV OF THE INVESTMENT PROJECT}

Net Present Value is an indicator used in order to compare projects realized in different periods of time and with different lengths. It

\footnotetext{
${ }^{1}$ Mises (1949) used the distinction for convertible and partially or nonconvertible capital: "It is expedient to substitute the notion of the convertibility of capital goods for the misleading distinction between fixed and free or circulating capital. The convertibility of capital goods is the opportunity offered to adjust their utilization to a change in the data of production."
} 
uses the discounted cash flow generated by the activity. The present value of delayed payoff can be found by multiplying the payoff by a certain discount factor, which is less than 1 . If the value of the discount factor was greater it would mean that the dollar tomorrow is worth more than a dollar today, which denies positive time preference. Net present value is defined as follows:

(1) $N P V=\sum_{t=0}^{n} \frac{C F_{t}}{(1+r)^{t}}$

where:

$C F_{t}=$ a cash flow to be received in a period of time $\mathrm{t}$,

$r=$ discount rate.

Ludwig von Mises and Irving Fisher suggest using the present value approach to economic calculation since the price of an investment project is moving towards the present value of the project's expected cash flows ${ }^{2}$. Present value approach was also advocated by Rothbard (1962, 62-63):

It is clear that the higher the rate of discount, the lower the present value of the future good will be, and the greater the likelihood of abstaining from the investment. On the other hand, the lower the rate of discount, the higher the present value of future goods will be on the actor's value scale, and the greater the likelihood of its being greater than the value of present goods forgone, and hence of his making the investment.

The consequences of interest rate changes and their effect on the valuation of projects were examined by Fuller (2013) and can be presented graphically:

\footnotetext{
${ }^{2}$ Both values are equal in equilibrium or in the Evenly Rotating Economy
} 
Figure 1. Net Present Value Profile

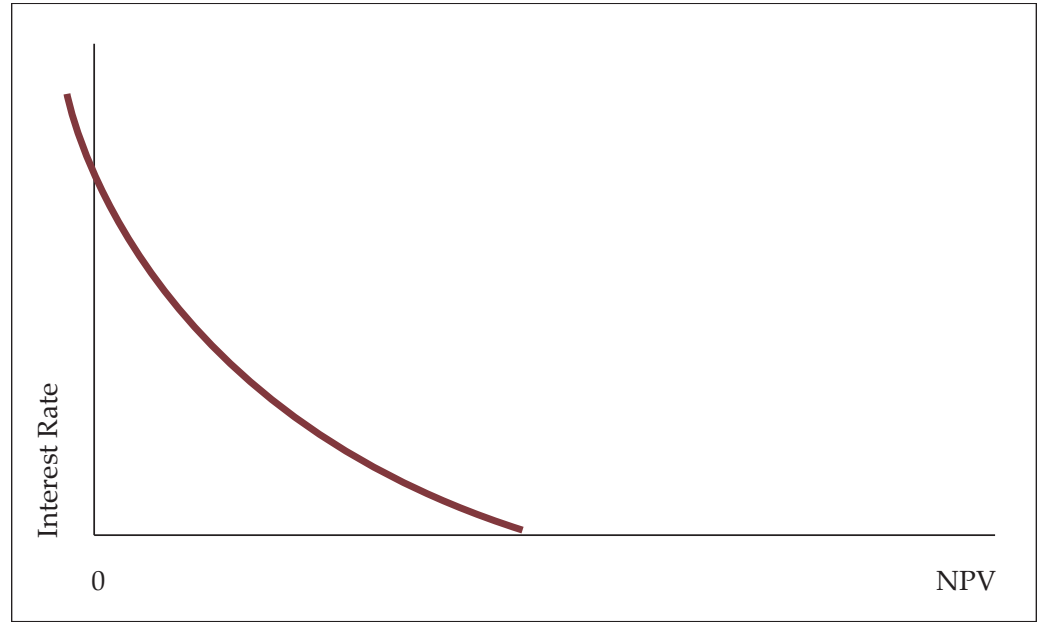

Diagram from Fuller (2013).

There are three indications of the NPV profile shape: the NPV of the project increases as the interest rate falls, the chart is curved, so the NPV profile becomes flattened as the interest rate falls, meaning that the change in interest rates causes not proportional change in NPV and this dependence is explicit in long term investment projects in particular, since the longer stream of cash flows is discounted. Third, the NPV profile intersects the interest rate axis at the point where NPV is zero, indicating the positive NPV area on the right from the vertical axis (Fuller, 2013).

If the present value is used as an indicator of a project's profitability, then the expected reinvestment rate should be used as a discount factor, since comparing two projects of a different outlays requires comparing in relative, rather than absolute terms. In that case, it is necessary to compare "present value per dollar of outlay" (Solomon, 1956). The valid comparison can be made not only with similar projects but also with two different courses of action, which can be brought to the same measure using NPV.

Wealth maximizing investors use NPV to rank their investment projects while competition in the market creates a tendency for the price of an investment project to equal the present value of expected 
cash flows. This is because investors will bid up the price when it is below the present value and bid it down when it is above, a simple arbitrage process. In the wooden and steel bridge example first described by Hansen $(1953,118)$ and later developed by Fuller (2013), there is presented the disproportionate effect of the change of the interest rate on the short-term and long-term projects. Since the lowering of interest rates favors longer projects, it is intuitive that these projects are usually associated with greater uncertainty, since they absorb resources for a longer period of time. The risk of the interest rate change may be one of the components that has an impact on how safe the particular investment is. For the purpose of expanding and quantifying this intuition, risk measures such as duration can be used.

\section{DURATION AS A RISK MEASURE}

One of the reasons for the 2007 crisis was aggressive profit targeting. As a result, agents tended to focus on the higher return from their investments, neglecting the difference in risk associated with their decisions. Since they were acting in the low rates environment, in the long term, more risky projects seemed more attractive as there was a possibility to achieve higher profits by engaging in these. That is the reason we cannot exclude risk from its role in the profitability of the investment projects, and this factor should be included in further analysis. It is not surprising that risk is positively correlated with higher potential profit. As a result of entrepreneurs being more likely to forecast consumers' demand in the near future, they generate greater errors in forecasting longer periods. Therefore, on average, there is a higher probability of erroneously forecasting more distant cash flow than those forecasts of cash flows to be received in the relatively near future.

In the short run, if we examine the wealth generated by the project without adjusting the forecasted values for risk, the output of the economy appears better when it is associated with an incipient boom. Consequently, in the medium or long run, collapse starts when this risk taken by the entities materializes. ${ }^{3}$ In the beginning, the projects

\footnotetext{
${ }^{3}$ Materialization of risk may be explained by an example: when a large number of companies engage in similar ventures, with a 70 percent probability of success each, it means that, on average, this will end up as a loss for about 30 percent of companies.
} 
generate positive cash flows and investments pay off, but eventually at least part of the risky investments will not succeed and the bust phase of the business cycle begins. Generally, the lower the interest rate, the more profitable investments in more roundabout projects appear. At the same time, the risk grows. This implies shifting the economy to a more risky position with higher potential returns (Cowen, 1997).

To quantify this risk, the risk-adjusted NPV as a measure of profitability should be used. Since wealth maximizing investors are evaluating projects only using risk-free NPV they may underestimate the risk associated with their investment decisions. One of the risk measures for the purpose of adjusting NPV for risk can be the duration measure. It was discovered and developed by Frederic Macaulay (1938) for the purpose of measuring the average time an investor waits to retrieve his money from an investment. Hicks independently derived "average period," an equivalent measure of elasticity, with respect to a discount ratio (Hicks 1939, 186). Although it has other applications, duration has been successfully used in problems regarding the reduction of basis risk, and even Macaulay himself was primarily focused on "the risk-proxying properties of his measure, despite the assigned name duration." (Cox, Ingersoll, and Ross, 1979) Although it was originally designed for bonds, it was later developed to be used effectively in capital budgeting (Blocker and Stickney, 1979). The duration is represented as follows:

$$
D_{r, n}=\frac{\sum_{t=1}^{n} \frac{C F_{t} t}{(1+r)^{t}}}{\sum_{t=1}^{n} \frac{C F_{t}}{(1+r)^{t}}}
$$

where:

$C F_{t}=$ a cash flow to be received units of time from today, beginning with $\mathrm{t}=1$ period from today,

$r=$ an appropriate discount rate for determining the present value of the cash flow,

$t=$ units of time.

The formula represents a weighted average of the stream payments, where the maturity of each payment is weighted by the proportion of the total value of an asset accounted for by the 
payment (Haugen 1990), so the duration, in a way, represents an average life of an asset.

For the purpose of capital budgeting, the duration can be measured as the duration of the net cash inflows and the duration of the net cash outflows (Durand 1974, 25). The properties of this measure, as Blocher and Stickney (1979) pointed out, are as follows:

1. The duration of a stream of cash flows is always less than the time of the last cash flow (unless the stream is single cash flow, in which case duration is equal to the number of periods which elapse until that last cash flow).

2. The difference between a project's life and its duration is relatively small for shorter-lived projects but increases as the life of the projects is increased.

3. Duration varies inversely with the discount rate used. The higher the discount rate, the shorter will be the time until the average present value dollar is received.

4. For a project with a zero or positive net present value at the certain discount rate used, duration increases at a decreasing rate as the foreseen life of the project is increased, but it is bounded.

5. Duration is relatively insensitive to the discount rate used for shorter-lived projects but becomes more sensitive to the discount rate as life is increased. (pp. 3-4)

When used in predicting bonds' prices, duration assumes a linear relationship between price and changes in interest rates. In reality, however, prices rise more than proportionally as interest rates fall and decrease at an increasing rate as interest rates rise. As a result, the duration will underestimate the price increase, meaning that the risk can still be undervalued.

To illustrate the calculation of duration we will use the following example: 
Table 1. Duration Calculation

\begin{tabular}{|l|l|l|l|l|}
\hline $\begin{array}{l}(1) \\
\text { Year }\end{array}$ & $\begin{array}{l}(2) \\
\text { Cash flow }\end{array}$ & $\begin{array}{l}(3) \\
\text { Present value } \\
\text { factor at } 5 \%\end{array}$ & $\begin{array}{l}(4)=(2) \times(3) \\
\text { Present value of } \\
\text { cash flows }\end{array}$ & $\begin{array}{l}(5)=(4) \times(1) \\
\text { Weighted } \\
\text { cash flow }\end{array}$ \\
\hline 1 & 10,000 & .95 & $9,523.81$ & $9,523.81$ \\
\hline 2 & 5,000 & .91 & $4,535.15$ & $9,070.29$ \\
\hline 3 & 2,500 & .86 & $2,159.59$ & $6,478.78$ \\
\hline 4 & 1,000 & .82 & 822.70 & $3,290.81$ \\
\hline 5 & 500 & .78 & 391.76 & $1,958.81$ \\
\hline & Sum & $17,433.02$ & $30,322.51$ \\
\hline
\end{tabular}

For this project, the duration is 1.74 and this is the number we receive by dividing the sum of the column (5) by the sum of the column (4).

Duration is also used as a measure of expected changes in market prices of bonds after a change in interest rates. The relation between duration $(D)$, price $(P)$ and interest rate $(r)$ is described by the equation:

$$
\text { (3) } \frac{d P}{P}=-D \frac{d r}{(1+r)}
$$

Meaning, ceteris paribus, the greater the duration, the more sensitive will be a bond's price to changes in the interest rate. The elasticity aspect of duration ensures its usefulness in capital budgeting decisions for the purpose of a measurement of a loss in the net present value of a project suffered from a change in required rates of return. In two comparable projects the shorter the duration, the less net present value of the project is vulnerable for interest rate changes (Blocher and Stickney, 1979) and the safer the investment, since the investors are waiting for the return, on average, for a shorter period of time. There is, however, a side effect of this approach: when investors expect the interest rate to fall, the investment in projects with a longer duration will experience a larger increase in their value than others, meaning that investors may shift to those projects if NPV valuation is not supported by further risk analysis. It may be perceived as the proper investment decision as long as the low interest rate environment is controlling. The problem is that 
longer investment projects are considered more attractive. But it is probable that the interest rate will increase during the project's life. That will change profitability drastically.

Since duration reflects the average length of time consumed waiting for receipt of the cash flow generated by the project, it also demonstrates the liquidity of the project. It competes in that area with a conventional payback method, ${ }^{4}$ but duration surpasses payback period in that function since only duration can be incorporated in the analysis of NPV, and not as a supporting indicator alone.

\section{DURATION EFFECTS ON NPV}

Since, as explained in the above analysis, investors after lowering interest rates are switching their preferences to more capital-intensive, longer-term investments, at the same time, on average, they turn to projects with a longer duration. This means that during the phase of the boom of the business cycle economy shifts to a more risky position. Since the agents are targeting profit, there is a little attention paid to the risk exposure, measured by duration, of their projects.

Taking into the examination the example presented by Fuller (2013) of the two alternative projects, the further analysis of two investment projects will be carried out: a wooden bridge requiring a lower financial expense of 2,000 units and providing a constant cash flow of 1,000 in the next 3 years, and a steel bridge requiring the expense of 5,000 units and providing 0 units cash flow for the next 2 years, and a constant 1,000 units for the following 8 years, which is presented in the following table:

\footnotetext{
${ }^{4}$ Payback period is the amount of time it takes to recover the cost of an investment
} 
Table 2. Cash Flows Schedule

\begin{tabular}{|l|l|l}
\hline Time & Wooden bridge & Steel bridge \\
\hline 0 & $-2,000$ & $-5,000$ \\
\hline 1 & 1,000 & 0 \\
\hline 2 & 1,000 & 0 \\
\hline 3 & 1,000 & 1,000 \\
\hline 4 & & 1,000 \\
\hline 5 & & 1,000 \\
\hline 6 & & 1,000 \\
\hline 7 & & 1,000 \\
\hline 8 & & 1,000 \\
\hline 9 & & 1,000 \\
\hline 10 & & 1,000 \\
\hline
\end{tabular}

The interest rate for which these projects generate the same net present value, meaning that they should be indifferent in the investors ranking, is approximately 5.48 percent. Discounted by this rate, the net present value of the projects is around 699.10 units. Calculating the duration for both provides more information about the expected returns. Since the duration for wooden bridge equals 1.96, and for the steel bridge it is 6.22, investors have to wait for returns from invested capital more than three times longer if they decide to invest in the steel bridge, which is associated with a higher risk for their income. But further assume that the investors demand a higher return and the interest rate increases from 5.48 percent to 7 percent. In this scenario, the net present value of the wooden bridge decreases only to 624.32 from 699.10, which is about an 11 percent decrease, while the steel bridge net present value decreases from 699.10 to just 215.56, which constitutes a 61 percent decrease, showing how sensitive projects with a large duration are to changes in interest rates.

This may explain why even a slight change in the interest rates may cause a dramatic change in the profitability of a project. Since in the present low rate environment, we expect that the average undertaken project has a longer duration, the expected vulnerability to the discount rate changes also increases. 
Table 3. NPV and Duration Schedule

\begin{tabular}{|l|l|l|l|l|l|l|l|l|l|}
\hline \multicolumn{9}{|c|}{ Wooden bridge } & \multicolumn{6}{c|}{ Steel bridge } \\
\hline $\begin{array}{l}\text { Interest } \\
\text { rate }\end{array}$ & Duration & NPV & $\begin{array}{l}\text { NPV } \\
\text { change }\end{array}$ & $\begin{array}{l}\% \text { change } \\
\text { of NPV }\end{array}$ & $\begin{array}{l}\text { Interest } \\
\text { rate }\end{array}$ & Duration & NPV & $\begin{array}{l}\text { NPV } \\
\text { change }\end{array}$ & $\begin{array}{l}\% \text { change } \\
\text { of NPV }\end{array}$ \\
\hline $1 \%$ & 1.99 & 941.0 & & & $1 \%$ & 6.45 & 2500.9 & & \\
\hline $2 \%$ & 1.99 & 883.9 & -57.1 & $-6 \%$ & $2 \%$ & 6.40 & 2041.0 & -459.89 & $-18 \%$ \\
\hline $3 \%$ & 1.98 & 828.6 & -55.3 & $-6 \%$ & $3 \%$ & 6.34 & 1616.7 & -424.29 & $-21 \%$ \\
\hline $4 \%$ & 1.97 & 775.1 & -53.5 & $-6 \%$ & $4 \%$ & 6.29 & 1224.8 & -391.93 & $-24 \%$ \\
\hline $5 \%$ & 1.97 & 723.2 & -51.8 & $-7 \%$ & $5 \%$ & 6.24 & 862.3 & -362.48 & $-30 \%$ \\
\hline $6 \%$ & 1.96 & 673.0 & -50.2 & $-7 \%$ & $6 \%$ & 6.20 & 526.7 & -335.63 & $-39 \%$ \\
\hline
\end{tabular}

To fully understand the duration's significance in NPV analysis we present selected values in the table. The first conclusion is that the greater the interest rate, the smaller the duration is. It is the result of the NPV profile. When we increase the discount factor used for future cash flows, the more advanced payments are getting a lower share in the total NPV sum compared to prior payments. As a result, using the duration interpretation, we do not wait as long for future cash generated by the project as we do when using the same payment with a lower interest rate, due to the fact that later payments are given less significance. It also must be noted that the duration changes associated with interest rate changes are not substantial and are even small for the shorter projects.

The second conclusion which we can derive from the values in the table is that the greater the duration, the greater NPV loss from the increase of the interest rate. It is worth noting that this is only true for nominal values. 
Figure 2. Duration Profile

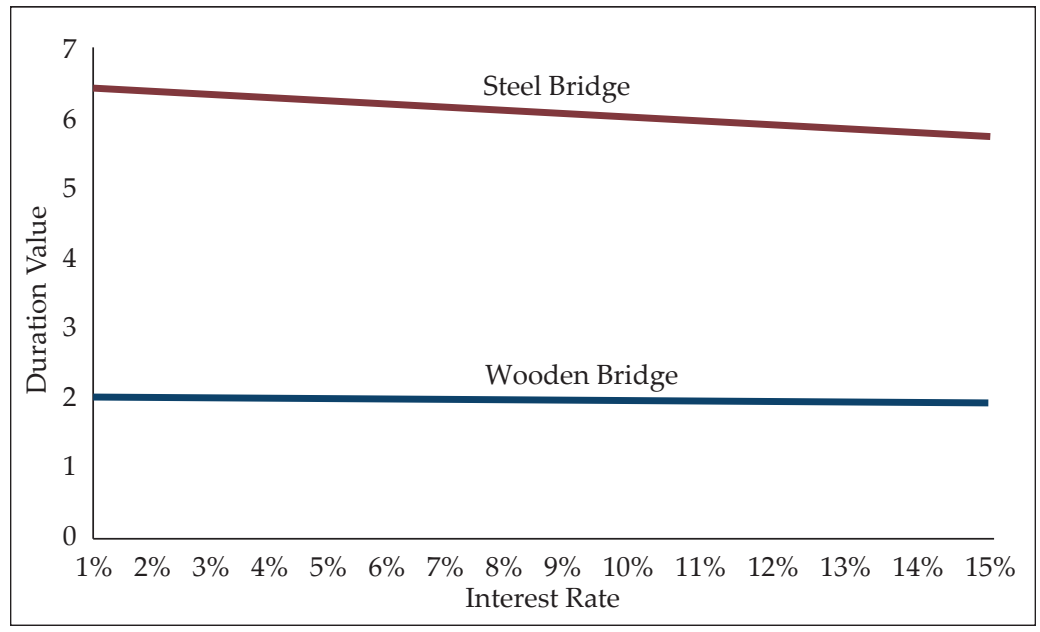

In Figure 2, different duration values for different interest rates are presented. Although changes are not significant, it can be easily seen that the values for duration for the shorter project, the wooden bridge, are steady. Despite the fact that the NPV and the returns from investment are changing, the average waiting period for the investor to recover his money from the investment is not. In case of the longer, more deferred project, we see a steady drop in duration value as the interest rate increases. Although, as we mentioned, generally shorter projects are less risky, in this case the decline in duration is associated with decreasing share of later payments in overall value. That means that the greater weight is given to the less distant payments, which is decreasing the duration, but at the same time NPV values are decreasing on a larger scale.

If the interest rate is artificially reduced by a central bank, the duration gap between shorter-lived and longer projects increases. This causes a greater hazard for the second type of projects as their payment is not only subject to interest rate risk, which can be measured by duration, but is also subject to the uncertainty associated with changing economic conditions of business.

Longer-term projects are more information sensitive and are subject to profitability changes due to uncertainty. Even though 
this is unquantifiable, the entrepreneurs have to make a prediction about the forecasted cash flows generated by the company investment decisions. As described by Ludwig von Mises (1951, 27): "There is no certainty about the future state of the market and about the height of these earnings. They can only be determined by speculative anticipation on the part of the entrepreneur."

The duration may prove useful to quantify at least some risks regarding the previously estimated profit not being realized. The duration may show that not every long term project is equally risky-e.g., risk may also depend on how flat the yield curve is for a particular project. $^{5}$

\section{RISK-ADJUSTED THE NET PRESENT VALUE}

Since the net present value is sensitive to interest rate changes, especially long-term projects should not be discounted with a nominal interest rate. Expanding the analysis for the illiquidity risk-adjusted interest rate could further develop the analysis. For projects in which annual cash flows constitute an annuity, the algorithm for the duration is reduced to:

(4) $D_{r, n}=\frac{1+r}{r}-\frac{n}{(1+r)^{n}-1}$

Where $r$ is the value which equates the present value of the inflows to the price of the investment. For project analysis it can be the yield rate, the cost of capital rate, a risk-adjusted rate, or any rate that an investor may use as a required rate of return (Brown and Kulkarni 1993).

To perform the NPV analysis, the company can estimate the discount rate for each project using the Capital Asset Pricing Model (CAPM) method. ${ }^{6}$ While it is not the method consistent with the Austrian theory, it is still one of the most popular tools used by large companies on the market, which is the reason we cannot neglect its importance. Graham and Harvey (2001) surveyed 392 CFOs about the cost of capital, capital budgeting, and capital structure. The

${ }^{5}$ The flat yield curve indicates that there is almost no difference between short-term and long-term rates for bonds and notes of similar quality.

${ }^{6} \mathrm{CAPM}$ defines the relationship between systematic risk and expected return for assets. 
results indicate that "the CAPM is by far the most popular method of estimating the cost of equity capital: $73.5 \%$ of respondents always or almost always use the CAPM. The second and third most popular methods are average stock returns and a multibeta CAPM, respectively" (Graham and Harvey 2001). CAPM is also popular among academics. Research conducted by Welch (2008) revealed that about 75 percent of finance professors still advocate using the CAPM to estimate the cost of capital. Furthermore, there is evidence that while the CAPM deliberately fails to predict asset prices, it is more useful for the purpose of estimating the cost of capital (Da, Guo, Jagannathan 2012). Even if we do not fully acknowledge the prediction made using the CAPM model including the duration in the equation may reduce the entrepreneurial mistakes caused by the non-risk-adjusted version of it, which is the reason the model is included in the paper.

The model determines the required rate of return for an investment as the sum of the risk-free rate $\left(R_{f}\right)$ and a premium, which is the product of beta and the difference between the market rate of return $\left(R_{m}\right)$ and the risk-free rate:

(5) $r=R_{f}+\beta\left(R_{m}-R_{f}\right)$

In order to obtain beta coefficients for investments, the method requires regressing the returns of the projects against the market returns, if available. In the case of the wooden and steel bridges, the most reasonable assumption is the beta coefficient for both projects moving in exactly same direction and having the same impact of changes on required return as a market ${ }^{7}$, meaning that beta equals 1 and using the market return of 5 percent (for which the steel bridge is a more attractive investment using net present value as an indicator). The risk-free rate is usually described as the government bonds' rate since they are currently considered the safest investment. We further make a conservative assumption that the risk-free rate is at 2 percent, meaning that 3 percent is the risk premium. ${ }^{8}$

\footnotetext{
${ }^{7}$ Beta belonging to the interval $(0,1)$ means that the investment is reacting slower than the market, and beta greater than 1 means that every time the market rate changes the required rate of return changes more than the market rate.

${ }^{8}$ The greater the risk premium, the greater impact duration will have on the risk-adjusted net present value. Since private investments usually have a few times higher return than the risk free rate, the 3 percent risk premium is a safe assumption.
} 
We will now try to adjust the net present value of the wooden and steel bridges from the example using the following equation presented by Brown and Kulkarni (1993):

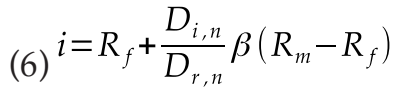

where:

$i=$ the rate of return adjusted for duration and timing of the cash flows

$r=$ the required rate of return on a project,

$D_{(i, n)}=$ duration of a project with periodic cash flow over $\mathrm{n}$ years discounted at the rate appropriate for the duration of that project

$D_{(r, n)}=$ the duration of a project with equal periodic returns over the project life of $\mathrm{n}$ years discounted at the $r$ rate

The equation derives from the standard CAPM equation with inclusion of liquidity adjustment coefficient $\left(D_{i, n} / D_{r, n}\right)$. A justification for including this ratio in the equation is that the "the ratio of duration of any project of $n$ years life to the duration of a uniform series project of the same life, when multiplied by the risk factor should produce a close approximation to what the rate should be to correct for duration" (Brown and Kulkarni 1993). Since $D_{r, n}$ is the function of only the project's life and rate and it assumes equal periodic returns over the life of the project, it can be calculated using equation (4) using $r$ just as in the CAPM model.

The values of $i$ and $D_{i, n}$ remain to be calculated. We know that for a project with a higher earlier duration, the risk is decreased, so adjusting for the duration of the projects also decreases the discount rate. This is analogous to the case of the projects with lower earlier cash flows. Therefore we know that if the duration of the project is less than $D_{r, n^{\prime}}$ then $i$ will be less than $r$, and $i$ will be greater than $r$ if the duration of the project is greater than $D_{r, n^{\prime}}$ as in this case. We find values of $i$ and $D_{i, n}$ in the following way: first, we assume $i=r$ and compute $D_{i, n}$ using (2). Then we find the difference between the left and right sides of (6). Therefore, we know whether our $i$ lies in the interval $[0, r]$ or $[r, \infty]$. Finally, we may use any method for finding roots, such as the bisection method, to find the value of $i$ that makes both sides of (6) equal, again using (2) for finding $D_{i, n}$. 
For a steel bridge the proper discount rate $i$ equals 5.65 percent with duration $D_{i, n} 6.21$. Since the wooden bridge generates stable cash flows every year $D_{i, n}=D_{r, n}$ for this project, this means that the discount rate for this project is the same as the initially used 5 percent.

Table 4. NPV and Risk-Adjusted NPV Comparison

\begin{tabular}{|l|l|l|}
\hline & Wooden bridge & Steel bridge \\
\hline Discount rate & $5 \%$ & $5 \%$ \\
\hline Net Present Value & 723.25 & 862.32 \\
\hline Corrected discount rate & $5 \%$ & $5.65 \%$ \\
\hline Net Present Value risk-adjusted & 723.25 & 639.64 \\
\hline
\end{tabular}

Even though the steel bridge seemed the more attractive investment at the 5 percent discount rate and was higher in the NPV ranking, after adjusting the discount rate for the risk, the new risk-adjusted NPV changed the valuation, and in the effect the safer investment: the wooden bridge project is preferred.

\section{CONCLUSION}

Since the net present value is a frequently used indicator of the profitability of projects, when we consider its disadvantages-volatility resulting from even subtle interest rate changes-enhancing this measure for quantification of this risk can provide further information for investors. Since the duration of a project captures the impact of both uncertainty of future income and sensitivity for interest range changes in low rate environments, it can be used as a measure for interest risk changes and as a factor in determining the risk-adjusted NPV value. As presented in this paper, adjusting for risk can produce a different order of profitability of projects, enriching the analysis and preventing more risk-averse investors from taking excessive risk, which inextricably linked with longer investment projects.

It is worth noting that using such models for the purpose of making future predictions may constitute a part of the entrepreneur's verstehen. In order to forecast future conditions of economic 
activity, entrepreneurs must use qualitative forecasts that are supported by his judgment. This was also the view emphasized by Rothbard (1997): "Misesian Man knows a lot; but he does not know everything and he must try to estimate the future, given various quantitative and qualitative estimates of change." Duration is definitely among important parameters which have to be taken under consideration by entrepreneurs.

Previous research on corporate finance was focused on the liquidation phase and depression (Cwik 2008) or the focus was placed on the roundaboutness of projects (Cachanosky, Lewin 2014). A deeper understanding of financial foundations of the business cycle can increase knowledge of the effects of an easy monetary policy along with a better understanding of causal relations between companies' decisions and any emerging crisis. While there is a common agreement about the wrong valuation of risk by companies throughout the business cycle, there is little evidence about the foundations of this factor underestimation. One of the reasons may be using measures that are not risk-adjusted and which may create an illusion of profitability in a current low rate environment.

\section{REFERENCES}

Blocher, Edward, and Clyde Stickney. 1979. "Duration and Risk Assessments in Capital Budgeting." Accounting Review 54, no. 1.

Brown, Robert J., and Mukund S. Kulkarni. 1993. "Duration and the Risk Adjustment of Discount Rates for Capital Budgeting." The Engineering Economist 38, no. 4: 299-307.

Cachanosky, Nicolas, and Peter Lewin. 2016. "Financial Foundations of Austrian Business Cycle Theory." Pp. 15-44 in Advances in Austrian Economics, Studies in Austrian Macroeconomics, vol. 20. Bingley, U.K.: Emerald Publishing Ltd.

— . 2018. "The Role of Capital Structure in Austrian Business Cycle Theory." Journal of Private Enterprise, 33: 21-32.

Cowen, Tyler. 1997. "Risk and Business Cycles: New and Old Austrian Perspectives." London, Routledge.

Cox, John C. 1979. "Duration and the Measurement of Basis Risk." Journal of Business 52, no. 1: 51-61. 
Cwik, Paul F. 2008. "Austrian Business Cycle Theory: A Corporate Finance Point of View." Quarterly Journal of Austrian Economics 11, no. 1: 60-68.

Da, Z., R. J. Guo, and R. Jagannathan. 2012. “CAPM for Estimating the Cost of Equity Capital: Interpreting the Empirical Evidence." Journal of Financial Economics 103, no. 1: 204-20.

Durand, David. 1974. "Payout Period, Time Spread, and Duration: Aids to Judgment in Capital Budgeting." Journal of Bank Research 5: 20-34.

Engelhardt, Lucas. 2012. "Expansionary Monetary Policy and Decreasing Entrepreneurial Quality." Quarterly Journal of Austrian Economics 15, no. 2.

Fuller, Edward W. 2013. "The Marginal Efficiency of Capital." Quarterly Journal of Austrian Economics 16, no. 4.

Graham, John R., and Campbell R. Harvey. 2001. “The Theory and Practice of Corporate Finance: Evidence from the Field." Journal of Financial Economics 60, nos. 2-3: 187-243.

Hansen, Alvin H. 1953. A Guide to Keynes. New York: McGraw-Hill.

Haugen, R. A. 1990. Modern Investment Theory. 2d ed. Upper Saddle River, N.J.: Prentice Hall.

Hicks, John R. 1975. Value and Capital. Oxford: Clarendon Press.

Johnson, Eldon C. 2005. "Duration: A Pedagogical Tool for Interest Rate Risk Analysis." Journal of Financial Education 31: 34-48.

Macaulay, Frederick. [1938] 1975. Some Theoretical Problems Suggested by the Movement of Interest Rates, Bond Yields, and Stock Prices in the US Since 1856. New York: National Bureau of Economic Research.

Machlup, Fritz. 1935. "The Rate of Interest as Cost Factor and as Capitalization Factor." American Economic Review 25, no. 3: 459-65.

Mises, Ludwig von. 1912. The Theory of Money and Credit. New Haven: Yale University Press.

—_. [1949] 1998. Human Action: A Treatise on Economics. Auburn, Ala.: Mises Institute.

—_. [1951] 2008. Profit and Loss. Auburn, Ala.: Mises Institute.

Rothbard, Murray N. [1962] 2009 "Man, Economy, and State." Auburn, Ala.: Mises Institute. 
. [1978] 1996. "Economic Depressions: Their Cause and Cure." Pp. 65-91 in The Austrian Theory of the Trade Cycle and Other Essays, ed. Richard M. Ebeling. Auburn, Ala.: Mises Institute.

. 1997. The Logic of Action One: Method, Money, and the Austrian School. Cheltenham, UK: Edward Elgar.

Solomon, Ezra. 1956. "The Arithmetic of Capital-Budgeting Decisions." Journal of Business 29, no. 2: 124-29.

Welch, Ivo. 2008. "The Consensus Estimate for the Equity Premium by Academic Financial Economists in December 2007." Available at https://ssrn.com/abstract=1084918.

Wood, J. Stuart. 1984. "Some Refinements in Austrian Trade-Cycle Theory." Managerial and Decision Economics 5, no. 3: 141-49. 